(c) 2020, The Authors. Published by FASS Inc. and Elsevier Inc. on behalf of the American Dairy Science Association ${ }^{\circledR}$. This is an open access article under the CC BY-NC-ND license (http://creativecommons.org/licenses/by-nc-nd/4.0/).

\title{
A virtual dairy herd as a tool to teach dairy production and management
}

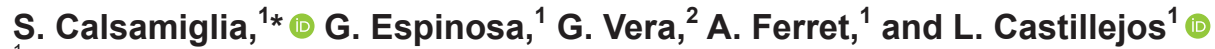 \\ ${ }^{1}$ Animal Nutrition and Welfare Service, Department of Animal and Food Sciences, Universitat Autònoma de Barcelona, Bellaterra 08193, Spain \\ ${ }^{2}$ Centre for Research in Agricultural Genomics, Universitat Autònoma de Barcelona, Bellaterra 08193, Spain
}

\begin{abstract}
The objective of this project was to develop and test a web-based virtual dairy herd to help students understand the structure and functioning of a dairy herd, and to promote active learning. At the beginning of the course, the instructor defines the profiles of herds to be assigned to students (e.g., herd size, production, diets, fertility). Each student has a unique herd and engages in decision-making for desired management practices in the herd. Modeled events are based on cow physiology and normal dairy herd management practices. Students' activities and decisions include heat detection, insemination, pregnancy diagnosis, dry-off, diet specifications, feeding groups, colostrum and milkreplacer feeding, weaning, treatment of diseases, and milk withdrawal from the tank if antibiotics are used, among others. The daily output provides information on technical indexes, economic performance, counters of incorrect decisions as feedback for students, and score. Time in class can be devoted to discussions of dairy management issues. Additional exercises based on students' own herds (e.g., calculating required space for cows, land for forage production, manure management) can also be implemented. Students' performance in the virtual dairy farm was monitored over 3 years. The average score $(\mathrm{n}=326)$ was $87.8 \pm 1.1$ over 100 points, suggesting that self-learning with the virtual dairy farm was highly successful. At the end of each semester, students $(\mathrm{n}=277)$ responded to a survey on the experience of working with the virtual dairy herd. Most students (>87\%) agreed that the virtual dairy herd was more effective and motivating than traditional lectures and helped them understand dairy production better. In an unannounced test conducted at least 2 wk before the final exam, students ( $\mathrm{n}=$ 207) were asked 14 questions on dairy cattle and 14 similar questions on other species taught in the same class through traditional lectures. A similar test on the same students $(\mathrm{n}=142)$ was conducted in their fifth
\end{abstract}

Received March 31, 2019.

Accepted November 11, 2019.

*Corresponding author: Sergio.Calsamiglia@uab.cat semester (2 years later). Results were better in dairy compared with other species questions in the first (9.6 vs. 3.7) and fifth (8.0 vs. 3.8) semesters. The virtual dairy herd is an effective tool for teaching introductory courses in dairy production. The program can be accessed at www.virtualdairyfarm.org, and a manual and videos with instructions for instructors and students are available online.

Key words: virtual dairy herd, dairy herd management, e-learning, teaching tool

\section{INTRODUCTION}

One of the main objectives of introductory courses in animal production is to expose students to a system where knowledge from different disciplines (reproduction, nutrition, management, physiology, health, economics, and others) is integrated. With traditional lectures, integration in introductory courses is difficult because it requires a good understanding of the system. Furthermore, teaching animal production is becoming more of a challenge due to the increasing numbers of students with no rural background in many agricultural and veterinary schools (Kensinger and Muller, 2006). General consensus exists that active learning improves the efficiency of the learning process (Wattiaux and Crump, 2006; Freeman et al., 2014). Practice and discussion strategies are better teaching methods than are lectures, readings, and demonstrations (TokuhamaEspinosa, 2010). To take students into farms where they can participate in herd-related daily activities and decisions would be highly motivating and would improve the learning process, but it is not always feasible, especially in introductory courses with large enrollment. Case studies are excellent to integrate concepts and "learn by doing" but also have problems: (1) they impose a burden on the instructor to generate a large number of cases and to grade them; (2) students need to have good bases to resolve cases; and (3) they require a high degree of motivation from students. With limited time and resources, how can today's instructors teach introductory dairy science courses with an integrated approach, to an increasingly nonrural population of students? The use of new technologies and the 
gamification of the classroom are alternatives that can be of help (Kensinger and Muller, 2006; Medrano et al., 2010; Maiga and Bauer, 2013). Computer simulation models for teaching have been used in many areas, but with limited application in animal sciences. However, some successful examples exist in specific areas such as genetics (Medrano et al., 2010), reproduction (Johnson et al., 1992), and manure management (Albrecht et al., 2006). Although these tools are very useful examples for teaching in these areas, a model that integrates the different management areas of a dairy herd does not exist.

We hypothesized that the use of a virtual dairy herd would motivate students, help them integrate the different management areas of the dairy herd, and improve the learning process. The objective of this project was to develop and test a virtual dairy herd to help students understand the structure and functioning of a dairy herd, and to promote active learning through a game-like environment.

\section{MATERIALS AND METHODS}

The project was developed in 2 steps: (1) development of the virtual dairy farm; and (2) evaluation of the virtual dairy farm as a learning tool.

\section{Step 1: Development of the Virtual Dairy Farm}

The software was programmed with JAVA language and runs in an Apache Tomcat server (Apache Software Foundation, Wakefield, MA). Herd events are based on cow physiology and normal management practices in small to medium conventional dairies using confinement facilities. Simulations run on a cow-by-cow and day-by-day basis. Calves are born male or female $(50 \%)$, inherit the milk production genetic potential of their dam, and are assigned a starting BW (40 kg) and height $(75 \mathrm{~cm})$. Newborn calves require actions such as ear tagging and navel disinfection during the first day of life, and colostrum feeding ( $3 \mathrm{~L}, 2$ times per day) on the first and second day of life. On d 3, calves should be moved to the milk-fed group, where they should be fed milk replacer (3 L, 2 times per day). Male calves should be sold after $8 \mathrm{~d}$ of life. Intake of concentrate will increase progressively after d 15 of life based on NRC (2001) equations. Growth rate is set by default for BW $(0.8 \mathrm{~kg} / \mathrm{d}$ from birth to first calving) and height $(0.14 \mathrm{~cm} / \mathrm{d}$ from birth to puberty and $0.07 \mathrm{~cm} / \mathrm{d}$ from puberty to first calving). Students may define different heifer feeding groups with different growth rates and costs. Weaning is determined based on the amount of concentrate consumed $(1 \mathrm{~kg}$ of $\mathrm{DM} / \mathrm{d})$. At puberty (300 $\mathrm{kg}$ BW), the ovarian cycle will start to occur regularly (every $21 \pm 3$ d) unless pregnancy occurs. During heat, heifers show estrous activity the day before and after mounting activity. Artificial insemination should occur only if animals have reached sufficient BW $(>350 \mathrm{~kg})$ and height $(>127 \mathrm{~cm})$ and there is mounting activity. Gestation $(278 \pm 5$ d) will depend on conception rate $(60 \%)$. Pregnancy can be diagnosed $34 \mathrm{~d}$ after insemination, but heat detection on d $21 \pm 3 \mathrm{~d}$ should be observed, to identify inseminated nonpregnant heifers and reinseminate them. Daily milk yield is determined based on Wood's lactation curve equations (Wood, 1967), taking into account the lactation number and DIM. After calving, cows return to cyclicity $(35 \pm 4$ DIM), and thereafter reproduction proceeds in a similar fashion to that of heifers, except for a lower conception rate $(40 \%)$. Cows should be dried off $60 \mathrm{~d}$ before the expected calving date.

Actual cow performance is affected by feeding, diseases, and management factors. Intake of DM is determined based on NRC (2001) equations. A default feed description and diet composition is provided, but instructors may change it to represent their local conditions. Nutrient requirements and supplies are simplified in terms of energy, $\mathrm{CP}$, and forage NDF (fNDF). Energy requirements are simplified to $10 \mathrm{Mcal}$ of $\mathrm{NE}_{\mathrm{L}} / \mathrm{d}$ for maintenance and $0.72 \mathrm{Mcal}$ of $\mathrm{NE}_{\mathrm{L}} / \mathrm{L}$ of milk produced, and protein requirements to $400 \mathrm{~g}$ of $\mathrm{CP} / \mathrm{d}$ for maintenance and $90 \mathrm{~g}$ of $\mathrm{CP} / \mathrm{L}$ of milk, based on NRC (2001). Energy and protein supplies are calculated by multiplying DM intake and nutrient content, and actual production is determined based on the most limiting nutrient. A minimum level of fNDF (19\%) is defined as the threshold for the incidence of acidosis. If acidosis occurs, then milk production $(-20 \%)$ and milk fat content $(-15 \%)$ are reduced. Students may define different feeding groups. Each group requires a description of diet ingredients and cost, and students have to move animals among groups to optimize performance and profitability.

Diseases are described based on occurrence and effects. Occurrence describes incidence, age, month of the year, DIM at risk interval, and duration of the disease. Effects describe the influence of disease on intake, milk yield and composition, SCC, return to ovarian cyclicity after calving, conception rate, abortion, risk of culling, and growth. Treatment may be applied to each disease. If treatment is applied, the duration of the disease is reduced, but there is an associated cost. If antibiotics are used, milk should be withdrawn from the tank for the days indicated in the treatment. New diseases can be added as long as the incidence and effects are described. Sick animals appear in the Sick tab within the Cow screen, and students are responsible for checking sick animal daily, applying appropriate treatment, 
and withdrawing milk from the tank if antibiotics are used. Default values for the most common diseases (mastitis, laminitis, retained placenta, metritis, ketosis, hypocalcemia, and displaced abomasum for cows; diarrhea and respiratory diseases for calves) are provided. The Disease menu can also be used to describe certain management or environmental factors. For example, heat stress is modeled by default, by assigning a reduction in DM intake $(-15 \%)$, milk production $(-15 \%)$, milk fat $(-5 \%)$, milk protein $(-5 \%)$, heat detection rate $(-50 \%)$, and conception rate $(-50 \%)$ for the summer months. Students will also have to decide to cull cows when the number of animals exceeds the maximum capacity of the herd. For every day simulated, the fixed and variable costs (such as feed, labor, utilities, semen costs, and health treatments) and income (sales of milk, calves, and culled cows) are calculated.

The software is structured with an administrator, instructors (with their associated courses), and students. The administrator can generate courses with a default herd profile and assigns one or more instructors. Instructors may modify the default herd to fit the objectives of the course and may also modify the settings at any time during the development of the course. Students manage their own unique herd in which cows are generated at random with a milk production potential of the herd average $\pm 2,000 \mathrm{~L} /$ cow per yr. The instructor also determines the starting date, the number of days to be simulated, and the deadline for completing all tasks. All changes implemented by the instructors are common to all students in the same class. The system allows generation of unlimited instructors, courses by instructor, and students within a course.

\section{Step 2: Evaluation of the Virtual Dairy Herd as a Learning Tool}

Evaluation of the tool was conducted in 3 consecutive years in the course "Bases of Animal Production" in the first semester of the Veterinary School of the Universitat Autònoma de Barcelona, with 120 students enrolled per year. The evaluation considered (1) students' performance using the virtual dairy herd for 150 $\mathrm{d} ;$ (2) a survey on student perceptions of the learning tool compared with traditional lectures; and (3) a test of knowledge at the end of the semester.

Students' Performance Using the Virtual Dairy Herd. A scoring system was developed to evaluate students' performance while working with the virtual dairy herd. The score accounted for students' incorrect decisions in different activities such as heat detection, insemination, dry-off, colostrum and milk-replacer feeding, weaning, transfer of animals between groups, treatment of diseases, and milk withdrawal if antibiotics are used. Incorrect decisions are those not done at the appropriate time or done at an inappropriate time. Bonus points can be obtained by adjusting the diet to optimize production and economic performance. All students start with 100 points. Points are lost based on percentage of incorrect decisions within each activity, and each activity accounts for a proportional fraction of the final score. This approach allows the student to recover lost points if the decision is repeated correctly because, as number of correct decisions taken increases, the percent of incorrect decisions are diluted.

Student Perception of the Learning Aid. Student perception of the usefulness of the methodology to understand dairy production was evaluated by administering a survey at the end of the first semester that contained 10 items to be scored between 1 (totally disagree) and 7 (totally agree; Table 1), and an overall score (1 to 100) for evaluation of the virtual dairy herd as a learning tool.

Test of Knowledge. We also conducted an unannounced test at least $2 \mathrm{wk}$ before the final exam. Students were tested on dairy cattle production concepts learned through the use of the virtual dairy herd and on production concepts for other species taught in the

Table 1. Survey of student attitudes toward the virtual dairy herd as a learning tool compared with conventional in-class lectures $(\mathrm{n}=277)$

\begin{tabular}{|c|c|c|c|c|c|c|c|}
\hline Item & \multicolumn{7}{|c|}{ Score frequency ${ }^{1}(\%)$} \\
\hline The virtual dairy herd helped you understand dairy cow production cycle & 0 & 1 & 1 & 6 & 22 & 43 & 27 \\
\hline The virtual dairy herd helped you understand other animal production systems & 1 & 0 & 1 & 4 & 19 & 34 & 41 \\
\hline Learning with the virtual dairy herd was more effective & 1 & 0 & 3 & 9 & 23 & 35 & 29 \\
\hline Working with the virtual dairy herd helped you to remember concepts of dairy production & 1 & 0 & 1 & 10 & 29 & 32 & 27 \\
\hline Virtual tools should be used more frequently in other species & 0 & 1 & 2 & 5 & 21 & 36 & 35 \\
\hline
\end{tabular}

${ }^{1} 1=$ totally disagree; $2=$ mostly disagree; $3=$ some disagreement; $4=$ equal; $5=$ some agreement; $6=$ mostly agree; $7=$ totally agree. 
Table 2. Questions used on the unannounced test to evaluate whether use of the virtual dairy herd improved short- and long-term retention of knowledge related to dairy cattle production compared with traditional lectures used to teach about other species

\begin{tabular}{ll}
\hline Questions related to dairy cattle & Questions related to other species \\
\hline Length of the ovarian cycle in a cow, d & Length of the ovarian cycle in a sheep, d \\
Length of gestation in a cow, d & Length of the ovarian cycle in a sow, d \\
When should a cow be dried off? & Length of gestation in a sow, d \\
Conditions required to inseminate a heifer & Length of gestation in sheep, d \\
Days of colostrum feeding to calves, d & When should a goat be dried off? \\
Amount of colostrum fed to calves, $\mathrm{L} / \mathrm{d}$ & Conditions required to inseminate a goat \\
When should a calf be weaned? & When should a piglet be weaned, d? \\
Amount of milk replacer fed to calves, $\mathrm{L} / \mathrm{d}$ & When should a lamb be weaned, d? \\
Price of cow's milk, $€ / \mathrm{L}$ & Slaughter weight of a lamb, kg \\
Price of an $8-$ mo-pregnant heifer, $€$ & Price of goat's milk, $€ / \mathrm{L}$ \\
Income from a culled cow, $€$ & Price of a pregnant ewe, $€$ \\
Mention $3-5$ ingredients of a dairy cow diet & Weight at slaughter of a broiler, kg \\
Peak production of a cow, $\mathrm{kg} / \mathrm{d}$ & Age at slaughter of a broiler, d \\
Average production of a cow, kg/d & Eggs produced by a layer hen per year, no. \\
\hline
\end{tabular}

same class using traditional lectures. The exam consisted of 14 questions related to dairy cattle production and 14 questions of the same type related to poultry, swine, or sheep production (Table 2). At the beginning of the fifth semester, 2 years later, the same students completed the same test without previous notice, to ascertain whether the method improved long-term retention of information.

Data were analyzed with SAS (v. 9.4; SAS Institute Inc., Cary, NC) and tested for normal distribution. Differences among years in students' performance in the virtual dairy farm exercise and in the survey data were analyzed using PROC MIXED, where year $(1,2,3)$ was the fixed effect. Scores of the unannounced test were analyzed using PROC MIXED, where year (1, 2, 3), semester (first vs. fifth), type of test (dairy vs. other species), and their interaction were fixed effects, and the student was the random effect. Differences were declared at $P \leq 0.05$.

\section{RESULTS AND DISCUSSION}

\section{The Virtual Dairy Herd}

The challenge of developing the tool was to balance animal biology and herd management practices with teaching and learning objectives. Furthermore, the software had to be flexible to allow adaptation to different scenarios, and the interface intuitive and easy to use by instructors and students. Interaction of students with the virtual dairy farm was achieved through 4 tabs to gain access to the respective screens: Indicators, Economy, Cows, and Calves. The Indicators screen provides information on initial and current herd performance (point A in Figure 1: milk yield and composition, fertility, and so on), overall score (point B in Figure 1, showing the example score 85 out of 100), and information about incorrect decisions (point $\mathrm{C}$ in Figure 1, showing 3 errors out of 16 heifer inseminations) as immediate feedback to students. The Economy screen is where daily income and expenses are calculated and the historical cash balance reported. As an example, Figure 2 shows the evolution of income and cost following a reduction in cost of feeding due to the introduction of high- and low-production groups by a student around d 16 of simulation (point A in Figure 2), and to increase income due to an increase in milk price programmed by the instructor around d 27 of simulation (point B in Figure 2). These are examples of changes that can be used by the instructor to demonstrate the influence of these and other decisions on herd performance and economics, making students aware of the relevance of proper management to herd profitability.

Most decisions take place in the Cows and Calves screens (Figure 3), where animals may be classified by any of the main technical indexes, which allows students to access animals in a specific condition (e.g., search for animals around d 21 in the ovarian cycle for heat detection; search for animals $220 \mathrm{~d}$ pregnant for drying off). Additional information on each animal can be accessed in the individual cow's card $(+$ signs in Figure 3). Figure 3 also shows a cow's individual card with the lactation curve (point A in Figure 3), mounting activity (point B in Figure 3), and specific decisions that may be taken on individual cows (inseminate, cull, or dry off). Cows may also get sick and, when sick, they should be treated. For example, point A in Figure 3 shows the lactation curve of a cow with a previous clinical metritis event, where milk production was reduced for several days and then recovered. If antibiotics are used for treatment, milk should be withdrawn from the milk tank for the required days to avoid being penalized. In fact, point $\mathrm{C}$ in Figure 2 shows the economic effect of not withdrawing milk containing antibiotics, where 
income for milk sales was zero for that day. Occurrence of diseases is designed to help students understand the consequences of their decisions on herd management, performance, and profitability. All events and decisions are recorded in an individual file for each cow.

\section{Evaluation of the Virtual Dairy Herd Tool}

Most students (typically 85\%) in the Veterinary School at the Universitat Autònoma de Barcelona (Spain) come from urban areas with limited or no rural background, which is becoming a common scenario in many veterinary and agricultural schools around the world (Kensinger and Muller, 2006). An introductory course in animal production is required in the first semester of the veterinary degree. Achieving the objectives of the class with a large enrollment (average of 120 students per semester) is difficult, due to the complexity of the concepts to be taught, the nonrural backgrounds of students, and the limited time available.
Students' Performance Using the Virtual Dairy Herd. The students' performance in the virtual herd exercise $(\mathrm{n}=326)$ was affected by year $(P<0.05$; $87.7 \pm 1.2,89.8 \pm 1.1$, and $86.1 \pm 1.0$, for years 1,2 , and 3 , respectively), with an overall average score of $87.8 \pm 1.1$, a median of 90 , and first and third quartile of 81 and 98, respectively. Only $2 \%$ of students scored less than 60. Results show not only excellent performance but also small variability among students. Part of the success of the tool relies on students' motivation and the fact that they get immediate feedback on their management decisions. When an incorrect decisions occurs, the score is reduced, and feedback is provided to the student, pointing to that decision. Because scores are calculated as a percent of incorrect decisions, increasing the number of correct decisions reduces the percentage of incorrect decisions, allowing improvement in the score. This calculation method rewards students who learn from their mistakes. This is a unique feature that transforms incorrect decisions into learning opportunities.

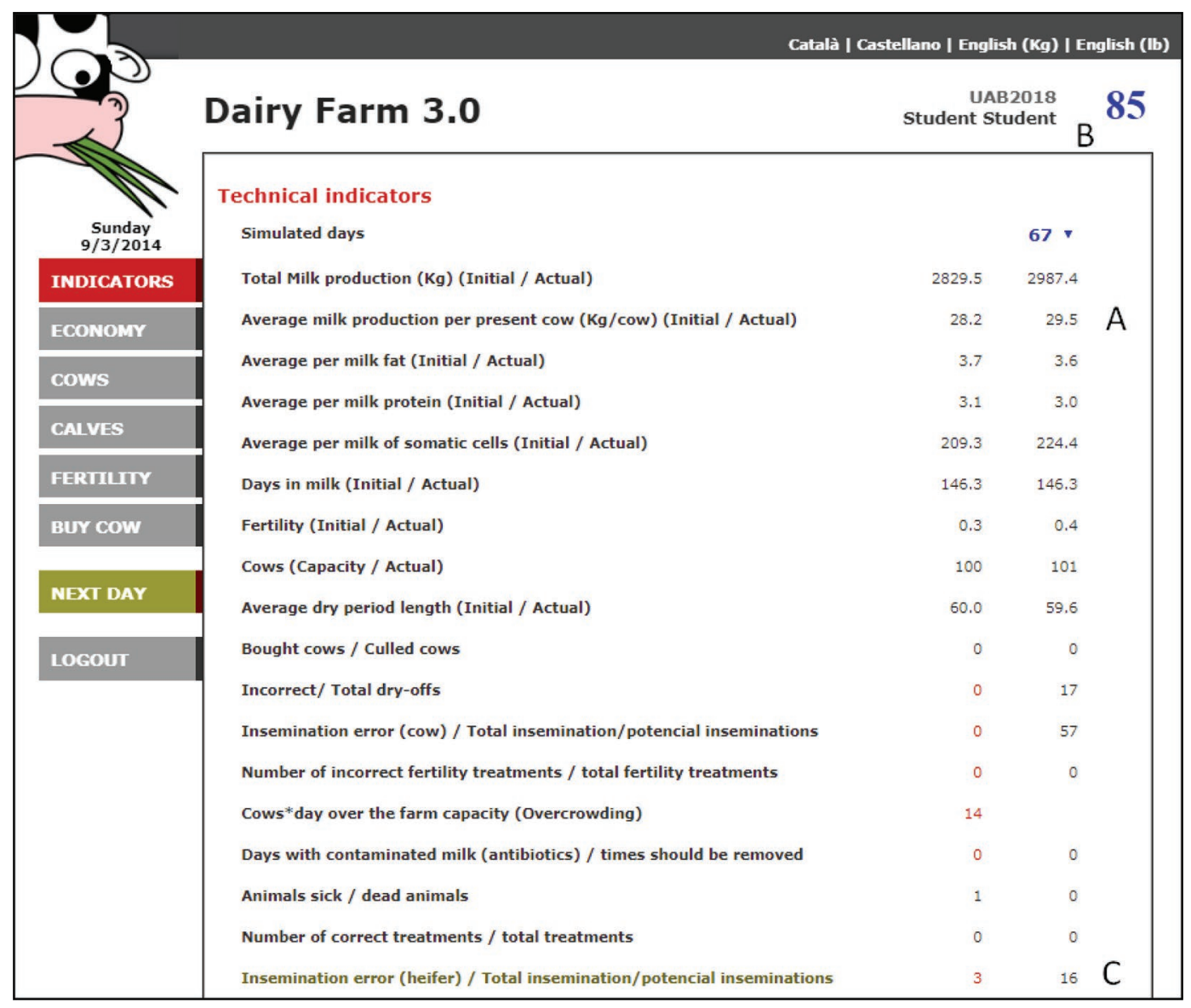

Figure 1. Partial view of the Indicators screen of the virtual dairy herd, describing technical indexes (point A, 29.5 L/d), current score (point $\mathrm{B}, 85$ points over 100), and counter of incorrect decisions (point C, 3 incorrect decisions out of 16 heifer inseminations). 
Student Perception of the Learning Aid. A survey conducted at the end of the semester for 3 consecutive years asked students $(\mathrm{n}=277)$ their perceptions of the usefulness of the virtual dairy farm compared with traditional lectures. Students' responses were not different among the 3 years. When students were asked to score the overall usefulness of the tool between 0 and 100 , the average was $83 \pm 2.6$. The frequency of responses for each specific question is shown in Table 1. Compared with conventional in-class lectures, $92 \%$ of students considered that the virtual dairy herd helped them to better understand the dairy cow production cycle, $70 \%$ consider that it helped them to better understand the functioning of a dairy herd, and $94 \%$ considered that it helped them to better understand animal production systems. Most students considered the virtual dairy farm more motivating (90\%) and more effective for learning (87\%) compared with traditional lectures. Students (69\%) also recognized that the tool increased their interest in other subjects related to animal production compared with traditional lectures. Most students (92\%) think that the virtual dairy farm should be used more often and in other species. Less than $7 \%$ of students preferred conventional lectures instead of the virtual dairy herd. About $42 \%$ of students would like to continue working with the virtual dairy farm beyond the required simulation days in the class, and $67 \%$ would participate in an interuniversity compe- tition, reflecting a high degree of motivation, considering that most students had limited prior knowledge.

Test of Knowledge. Results of an unannounced test conducted at least 2 wk before the final exam confirmed the perception that the virtual farm was a useful learning tool. It is a common concern for instructors that most students will study class material only in the weeks before the exam, which results in short-term memorization of facts. Therefore, the quiz was intended to test the hypothesis that continuous work with the virtual dairy farm allowed students to better gain and retain knowledge. Over the 3 years monitored, the test was completed by 208 students in the first semester and 122 students 2 years later, in the fifth semester. Year was not significant $(P>0.05)$, but we found an interaction of type of exam (dairy vs. other species) by semester $(P<0.05)$. Scores were higher in questions related to dairy production compared with equivalent questions on other species taught through traditional lectures in the first (9.6 vs. 3.7 over 14 questions; $\mathrm{SE}=0.15 ; P<$ $0.05)$ and fifth semester (6.9 vs. 3.8 over 14 questions; $\mathrm{SE}=0.19 ; P<0.05)$, although the score of the dairy section decreased slightly in the fifth compared with the first semester. Results indicate that persistent work with the virtual dairy herd improved short- and longterm learning compared with traditional lectures.

Through use of the virtual dairy herd, students were able to learn about (a) the biological cycle of cattle from

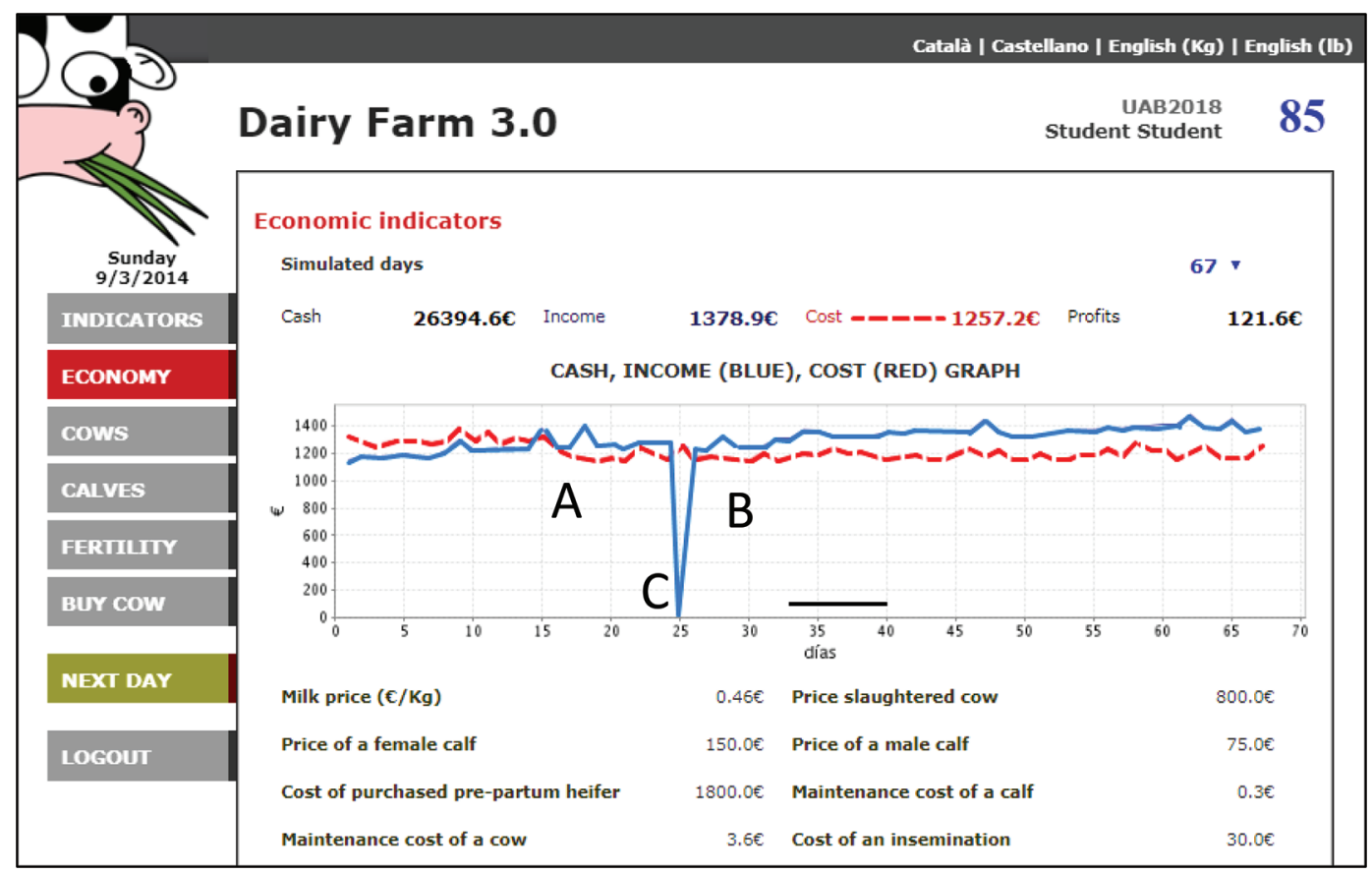

Figure 2. Economy screen in virtual dairy herd. Evolution of income (solid line) and expenses (dashed line), daily balance, and total cash available. The graph shows a reduction in daily costs around d 16 due to the implementation of 2-group feeding (point A), an increase in income due to an increase in milk price at d 27 (point B), and lack of income at d 25 due to the presence of antibiotics in milk (point C). 
birth to production; (b) reproduction management, such as puberty detection, heat detection, insemination at specific criteria, and pregnancy diagnosis; (c) the role of proper nutrition (e.g., modifying the diet to increase or decrease energy or protein supply, evaluating milk production and economic benefits, assigning different feeding groups); (d) the effects of prices of milk and feeds; (e) the relevance of a disease, as through lost production, shorter duration if treated, and the need to withdraw the milk from the tank if antibiotics are used; (f) management of heifers and the effects of growth on puberty and proper insemination timing criteria (body weight and height).

\section{Class Organization}

The virtual dairy farm has been used for 9 years in our introductory animal production courses in the Veterinary School at the Universitat Autònoma de Barcelona, after which we can draw some recommendations. We used a standard herd with 100 to 120 adult cows and their respective replacement heifers. The instructor may change the default description of the herd or the simulation conditions for the class. Figure $4 \mathrm{~A}$ shows a screenshot of the default reproduction criteria, where the instructor can introduce modifications on technical indexes. Students will manage their own herds, and the main objective is to let students learn the basic management activities in a dairy herd (Table 3): heat detection, insemination, reproductive cycle, dry-off, prices of feeds and milk, newborn calf management, milk-replacer feeding, weaning, reproduction in heifers, basic health issues, and the importance of antibiotic residues in milk, among others. In a standard class, students are required to simulate $150 \mathrm{~d}$. Reviewing all daily activities in the herd takes about 2 to 3 min per day simulated. If the student's task is to simulate 150 $\mathrm{d}$, then the expected workload to complete the exercise will be 5 to $8 \mathrm{~h}$. The instructor has access to all students' herds to follow up the exercise (Figure 4B). The introduction to the virtual dairy herd requires about 1 $\mathrm{h}$ of lecture to describe the production cycle of dairy cows and $1 \mathrm{~h}$ of hands-on computer training to teach students how to use the software. No additional formal training is done. Students are fully responsible for the management of their own virtual dairy herd. Students

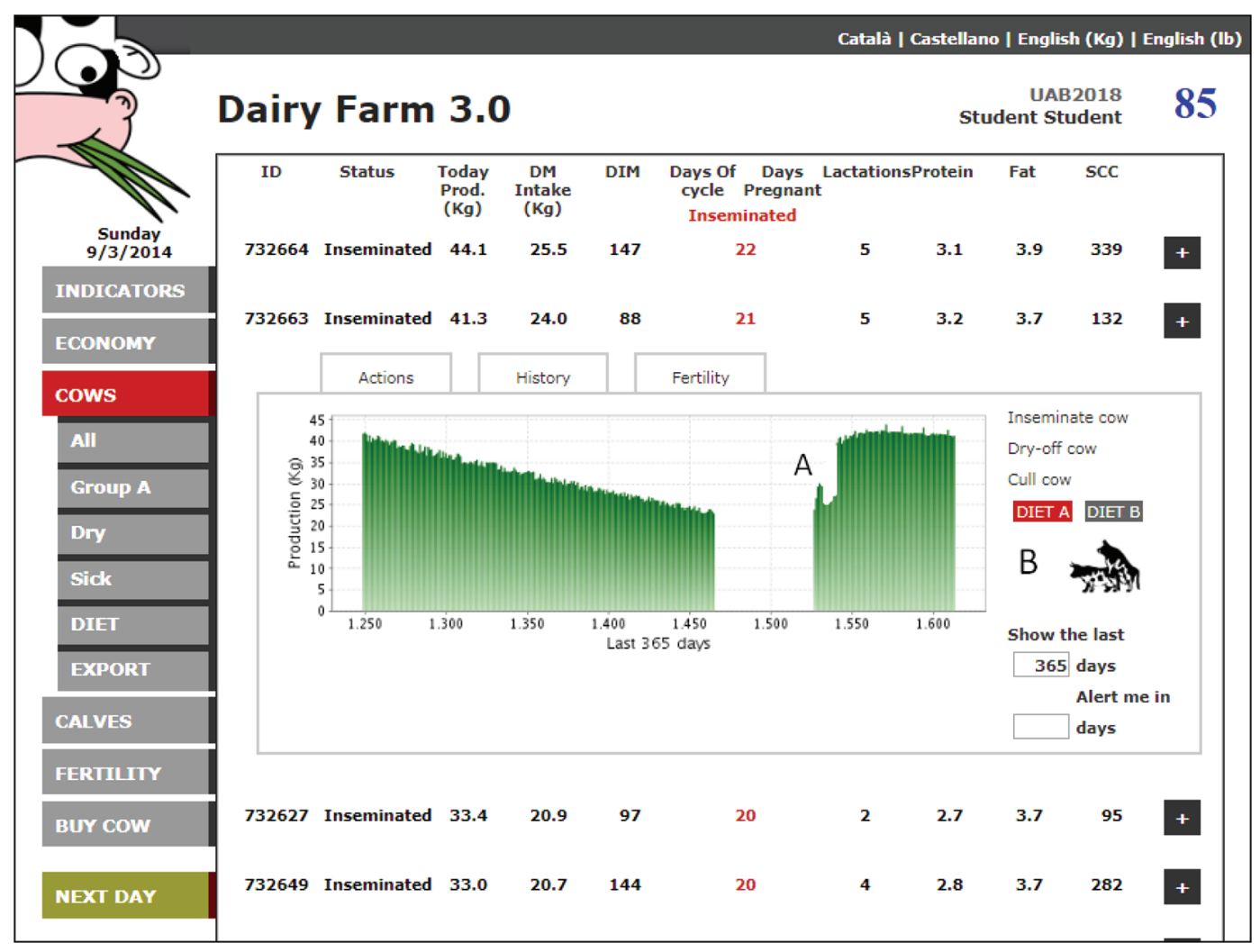

Figure 3. Cows screen in the virtual dairy herd, showing major technical indicators of all cows. The left-side submenu provides access to cow's groups, sick cows, and diets. The individual cow card (shown by clicking on the + sign) provides information on lactation curves, where a metritis event reduced milk production from d 8 to 21 postpartum (point A), estrus activity (point B), and decisions that may be taken (insemination, dry-off, or culling of cow). 


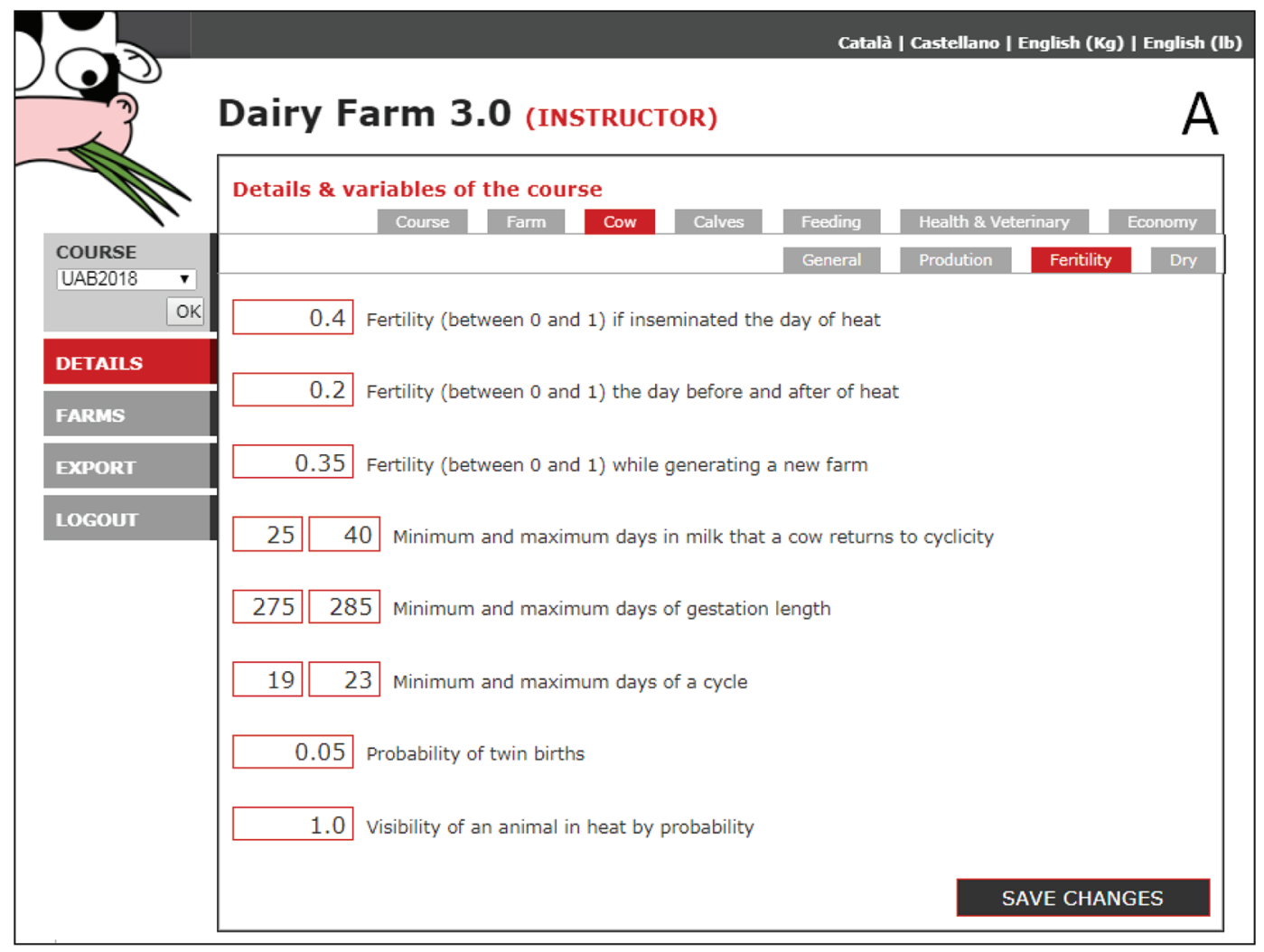

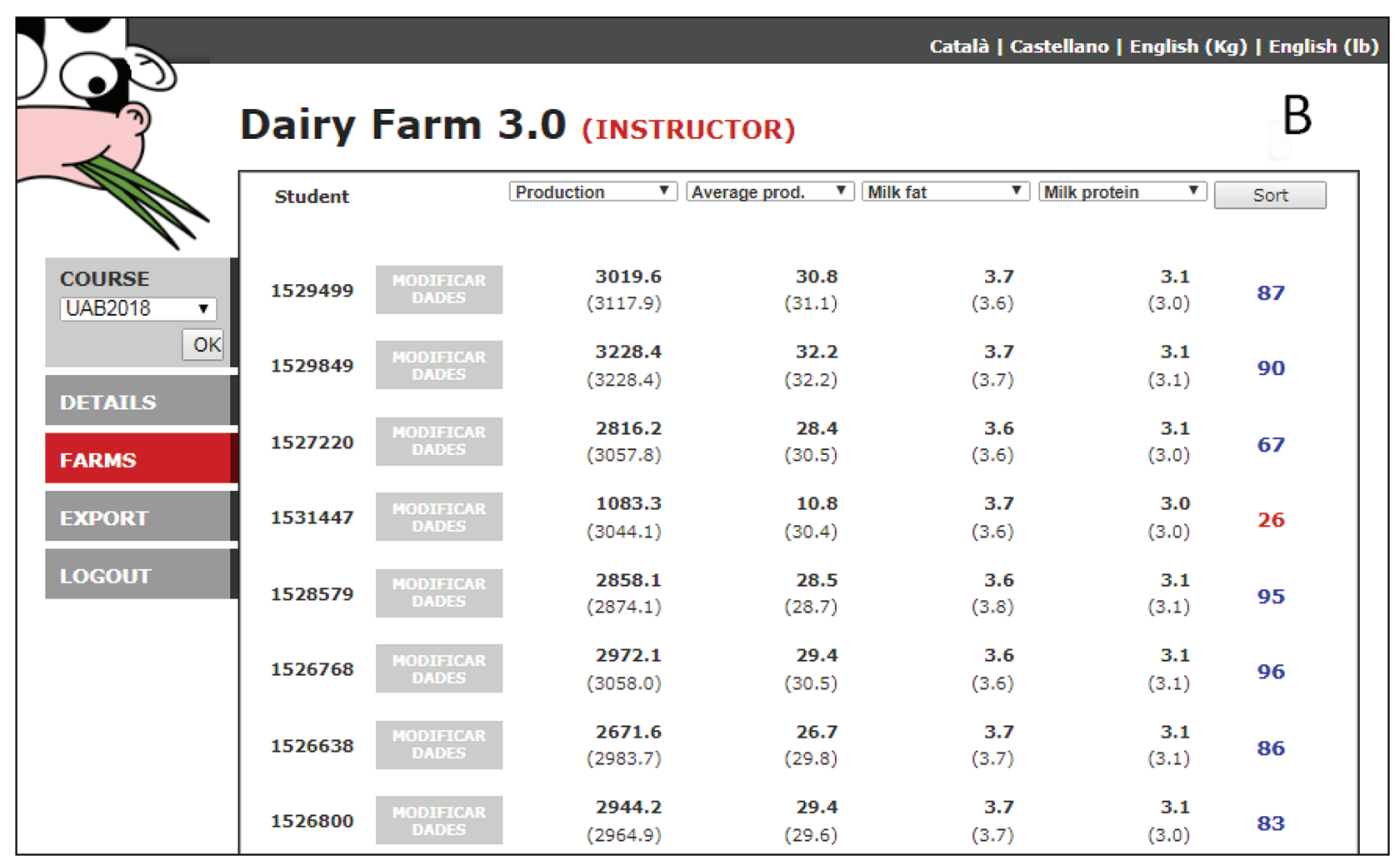

Figure 4. Instructor screens in virtual dairy herd. (A) Instructors have access to a set of screens where default values for a class can be modified (e.g., fertility of cows inseminated on the day of mounting activity is 40\%). (B) Instructors have access to all students' herds to consult about their activities (e.g., student 1529499 has an average production of $30.8 \mathrm{~L} / \mathrm{d}$ and a final score of 87). 
Table 3. Physiological events and management decisions that need to be performed by students in the virtual dairy herd

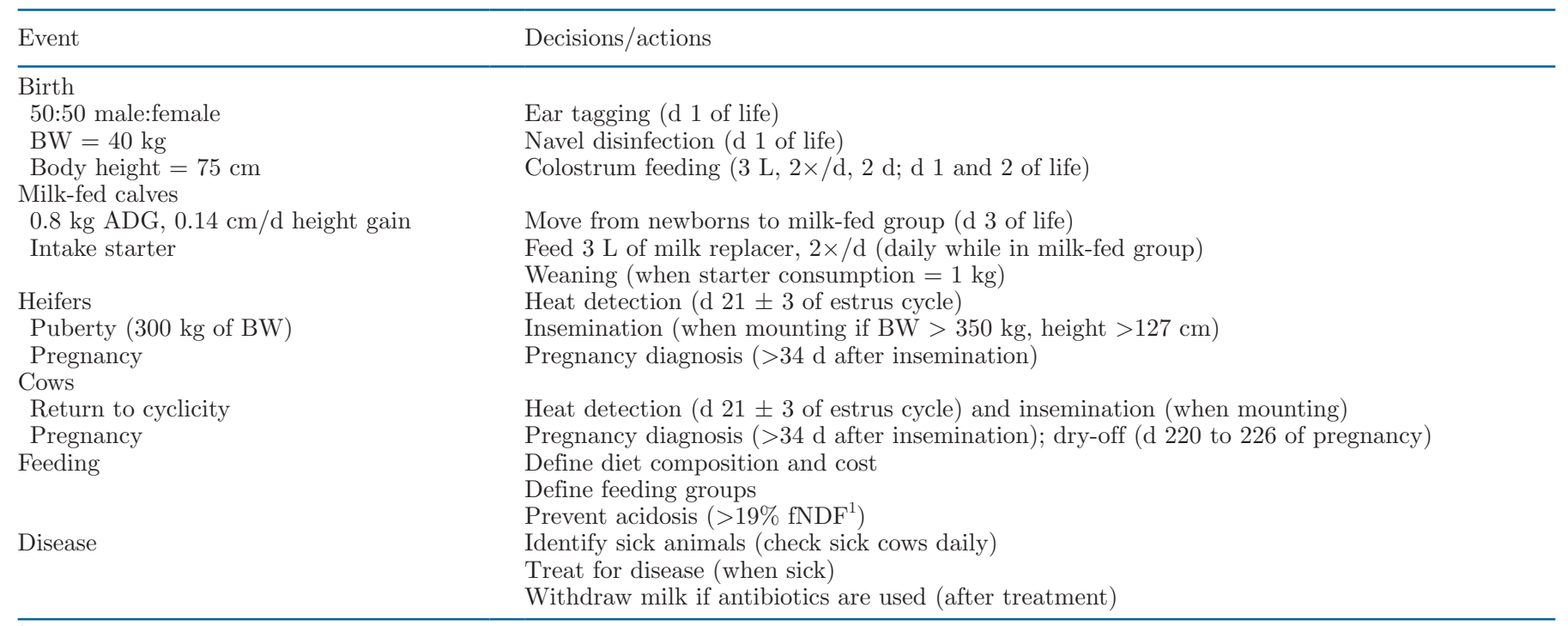

${ }^{1} \mathrm{fNDF}=$ forage NDF.

may help each other, but each student has to run his or her own herd. The instructor has certainty that each student has managed his or her herd and does not have to grade each student individually, allowing implementation of the system in large classrooms.

In a typical class, in addition to the daily herd activities, other exercises can be introduced at different times. For example, the instructor may introduce one or more changes after $50 \mathrm{~d}$ of simulation, to challenge students. For example, the instructor might (a) reduce the NDF content of forages to cause acidosis, which will prompt students to troubleshoot the problem and modify the diet accordingly; (b) change the prices of milk or feeds to increase awareness of the importance of prices on profitability; or (c) change the incidence of a specific disease. These changes can be introduced during the development of the exercise, and the consequences become the objective of an in-class discussion. These discussions are very motivating, because any input from the discussion can be applied by each student in his or her own virtual dairy herd. Furthermore, inclass discussions are recognized as an effective teaching method (Chickering and Gamson, 1991; Cameron, 2003; Wattiaux and Crump, 2006). The virtual dairy herd can also be used to ask students to conduct additional exercises. Some exercises we have used in the classroom include (1) calculating the amount of manure produced (total DM and N per year) and total hectarage of land required for its distribution, increasing student awareness of environmental issues; (2) calculating the land required for production of different forages or designing the sizes of different silos; and (3) drawing at scale the layout of the facilities, including feedbunk space, drink- ing space, and space for different types of animals in the herd (i.e., milking and dry cows, calves, and heifers).

Finally, throughout the semester, students visited farms from all species studied as part of the required class activities. A remarkable outcome in the visit to the dairy farm was that students were very motivated to ask questions of farmers and reacted to answers with their virtual dairy herd as a benchmark. This higher level of engagement - and, thus, the greater educational value derived from interacting with the dairy producer during the farm visits - was most likely the result of engaging with the virtual dairy herd. Thus it appears that the virtual dairy herd enhances the value of the field trips, and, possibly, the reverse was also true.

The virtual dairy herd is available in Catalan, Spanish, and English (units in $\mathrm{kg}$ and $\mathrm{lb}$ ), and is accessible free at www.virtualdairyfarm.org. The website contains a manual and short videos with introductions for instructors and students on how to use it. To activate an account as instructor, send a request to info@ virtualdairyfarm.org.

\section{CONCLUSIONS}

The web-based virtual dairy herd is an excellent tool to generate an unlimited number of herds to let students independently control selected daily activities of a dairy herd operation. The immediate feedback helps students identify incorrect decisions, and automatic scoring allows for use in large classrooms without the burden of individual corrections. Students' self-learning with the tool allows additional time for in-class discussions. The virtual dairy herd can be tailored for use 
in different environments and with different objectives. Results of the exercise, the test, and a survey show that the virtual dairy herd is an effective learning tool that helps students learn and understand dairy production in a motivating and integrated way.

\section{ACKNOWLEDGMENTS}

This project was funded by the Generalitat de Catalunya (Barcelona, Spain) under the program Improving of Teaching Quality (Project MQD2010-00170). The authors have not stated any conflicts of interest.

\section{REFERENCES}

Albrecht, G. L., Q. M. Ketterings, K. J. Czymmek, E. M. Van Amburgh, and D. G. Fox. 2006. Whole farm nutrient management: Capstone course on environmental management of dairy farms. Nat. Sci. Educ. 35:12-23. https://doi.org/10.2134/jnrlse2006.0012.

Cameron, V. L. 2003. Teaching advanced genetics without lectures. Genetics 165:945-950.

Chickering, A. W., and Z. F. Gamson. 1991. Applying the seven principles for good practice in undergraduate education. New Directions for Teaching and Learning. 47:5-7.

Freeman, S., S. L. Eddy, M. McDonough, M. K. Smith, N. Okoroafor, H. Jordt, and M. P. Wenderoth. 2014. Active learning increases student performance in science, engineering, and mathematics.
Proc. Natl. Acad. Sci. USA 111:8410-8415. https://doi.org/10 $.1073 /$ pnas.1319030111.

Johnson, P. J., P. A. Oltenacu, and R. W. Blake. 1992. LEARNREPRO: A computer-assisted training program for teaching dairy reproductive management. J. Dairy Sci. 75:2288-2293. https://doi .org/10.3168/jds.S0022-0302(92)77990-9.

Kensinger, R. S., and L. D. Muller. 2006. Major advances in teaching dairy production. J. Dairy Sci. 89:1155-1162. https://doi.org/10 .3168/jds.S0022-0302(06)72184-1.

Maiga, H. A., and M. L. Bauer. 2013. Using interactive flash games to enhance students' learning in animal sciences. NACTA J. 57:6-66.

Medrano, J. F., A. Ahmadi, and J. Casellas. 2010. Dairy cattle breeding simulation program. A simulation program to teach animal breeding principles and practices. J. Dairy Sci. 93:2816-2826. https://doi.org/10.3168/jds.2009-2640.

National Research Council. 2001. Nutrient Requirements of Dairy Cattle. 7th rev. ed. National Academy Press., Washington, DC.

Tokuhama-Espinosa, T. 2010. The New Science of Teaching and Learning. Teachers College Press, New York, NY.

Wattiaux, M. A., and P. Crump. 2006. Students' perception of a discussion-driven classroom environment in an upper-level ruminant nutrition course with small enrollment. J. Dairy Sci. 89:343-352. https://doi.org/10.3168/jds.S0022-0302(06)72100-2.

Wood, P. D. P. 1967. Algebraic model of the lactation curve in cattle. Nature 216:164-165. https://doi.org/10.1038/216164a0.

\section{ORCIDS}

S. Calsamiglia @ https://orcid.org/0000-0002-0978-3799

L. Castillejos @ https://orcid.org/0000-0001-7762-192X 